\title{
Infrared and NMR studies of probes in binary solvent systems
}

\author{
Martyn C. R. Symons \\ Department of Chemistry, The University, Leicester, LEl 7RH, U.K.
}

\begin{abstract}
The spectra of a variety of probe molecules have been measured for low concentrations in a range of pure and mixed solvents. These include triethylphosphine oxide [Et ${ }_{3} \mathrm{PO}:{ }^{31} \mathrm{P}$ and $v_{\mathrm{PO}}$ ], trimethylphosphate [Me ${ }_{3} \mathrm{PO}_{4}:{ }^{31} \mathrm{P}$ and $\nu_{\mathrm{PO}}$ ], hexamethylphosphoramide [HMPA: ${ }^{31} \mathrm{P}$ and $\nu_{\mathrm{PO}}$ ], acetone and various esters $\left[{ }^{13} \mathrm{C}\right.$ and $v_{\mathrm{CO}}$ ] and cyanomethane [MeCN: ${ }^{{ }^{3}}{ }^{1} \mathrm{C}^{1{ }^{14} \mathrm{~N}}$ and $\left.v_{\mathrm{CN}}\right]$. Infrared spectra often reveal the presence of several different transitions, indicating the presence of well-defined solvates. Hence for solutions in protic solvents it can be shown that tri-, di- and monosolvates may be present, as well as non hydrogen-bonded species. For given binary solvent mixtures (protic and aprotic) the relative concentrations of these solvates are estimated. Hence, in certain cases, trends in NMR shifts for the probes can be reproduced using the infrared data and, hence, unambiguous interpretations can be found.
\end{abstract}

\section{INTRODUCTION}

During the past thirty-two years, my collaborators and I have applied spectroscopic techniques to the study of solvation. Starting with the ultraviolet (CTTS) spectra of anions (refs. 1-3) in a range of solvents, we moved to studying the e.s.r. spectra of anions both 'free' and ion-paired (ref. 4), and the infrared and n.m.r. spectra of solvent molecules, especially water and protic solvents (refs. 5-7). We have recently started to use "probe" molecules to study solvation (refs. 8-11) and this Review is concerned with the results obtained. Although previous work of this type has been undertaken, it has not been systematic, and has largely been concerned with changes in n.m.r. (ref. 12) or e.s.r. spectra (refs. 13-15) of probe molecules. As is shown below, these techniques often give only a time average view of the solutions, and the shifts are consequently difficult to interpret. However, by using infrared methods, we have been able to glean more information, because averaging is slow, and this has helped in the interpretation of magnetic resonance shifts.

One advantage of studying "probe" molecules is that concentrations are low and probe-probe interactions can generally be ignored. Thus, only interactions with solvent molecules are important. Another is that for infrared studies, the number of oscillators can be kept constant so that families of curves are built up which show directly when specific changes occur. [Also, it is not necessary to use very short pathlengths or reflection techniques for strong oscillators.]

In favourable cases, infrared shifts are large, relative to line-widths, and n.m.r. shifts of pertinent nuclei are also large. In such cases, there are clear correlations between the infrared and n.m.r. results. One of the best examples is triethylphosphine oxide, Et ${ }_{3} \mathrm{PO}$. This is a particularly important probe since the ${ }^{31} \mathrm{P}$ shifts obtained for this compound in a range of solvents were used by Gutmann and coworkers (ref. 12) as a measure of the "acceptor number" of these solvents. This choice was wise, since the shifts are large, and welldefined for individual solvents. I therefore introduce the subject by summarising our results for $\mathrm{Et}_{3} \mathrm{PO}$, using pure solvents. Results for a variety of other probes in pure solvents are then described in Section A, before turning to the more revealing results for mixed protic + aprotic solvents in Section B. In Section C, mixed protic solvents are illustrated by reference to water-methanol mixtures.

\section{A. PROBES IN PURE SOLVENTS}

\section{Triethylphosphine oxide}

For most solvents, the infrared spectra in the $\mathrm{P}-\mathrm{O}$ stretch region were single, symmetrical bands with well-defined maxima $\left(\nu_{\max }\right)$ (ref. 8$)$. These are plotted against the corresponding ${ }^{31} \mathrm{P}$ chemical shifts in Fig. 1. However, for solutions in alcohols, two infrared bands were 


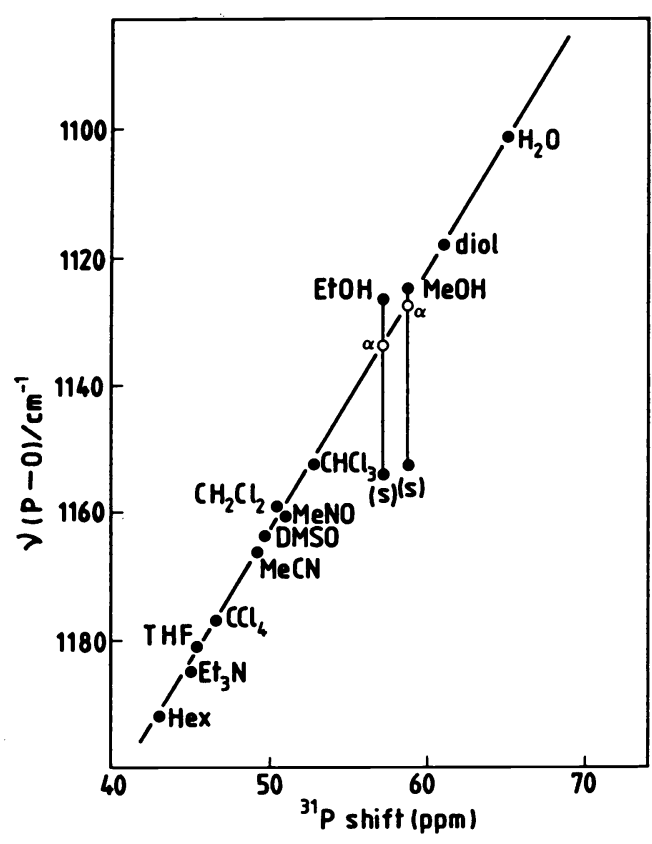

Fig. 1

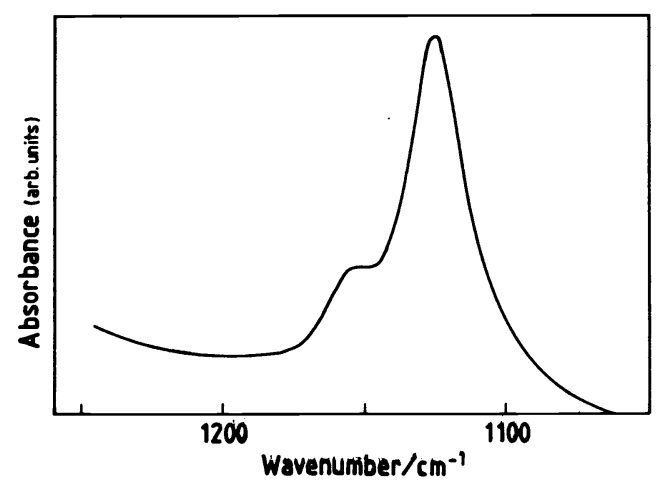

Fig. 2

Fig. 1. Correlation between ${ }^{31} \mathrm{P}$ resonance shifts and $\nu(\mathrm{P}-\mathrm{O})$ for $\mathrm{Et}_{3} \mathrm{PO}$ in dilute solution in a range of pure solvents. [ $\mathrm{Et}_{3} \mathrm{~N}=$ triethylamine, $\mathrm{THF}=$ tetrahydrofuran, Hex = hexane, DMSO = dimethylsulphoxide, diol = ethane1,2-diol.]

Fig. 2. Infrared spectrum for a dilute solution of $\mathrm{Et}_{3} \mathrm{PO}$ in methanol in the $\nu(\mathrm{P}-\mathrm{O})$ region.

detected (Fig. 2). In these cases, after using a computer to define the separate bands, weighted mean shifts were calculated (see below) and these are used in the correlation of Fig. $1(\underline{\alpha})$. It is noteworthy that whilst there is no correlation for the individual bands, the weighted mean values give excellent correlations. This underlines the fact that the n.m.r. results are, themselves, weighted mean values of all the shifts for individual species in solution. They show that there are two distinct types of Et ${ }_{3} \mathrm{PO}$ units, which, as I show later, are molecules forming either one or two hydrogen bonds to alcohol molecules. This shows the power of the infrared method, and also shows how n.m.r. shifts can be predicted fram the weighted mean values for a set of infrared bands. Indeed, as I show in Sections B and $C$, the correlation in Fig. 1 can be used very effectively to predict n.m.r. shifts for mixed solvent systems. Note that Fig. 1 also demonstrates that the infrared shifts correlate very well with the solvent acceptor numbers (A.N.) since, of course, these are the ${ }^{31} \mathrm{P}$ chemical shifts.

At this stage no definite conclusions can be drawn from the results regarding solvation numbers. However, they show that triethylamine is remarkably inert, the shifts from hexane being about half those for tetrachloromethane. The larger shift caused by $\mathrm{CHCl}_{3} \mathrm{Could} \mathrm{be}$ due to weak hydrogen bonding. The remarkably large shift induced by water is usually taken to mean that water forms strong hydrogen bonds to basic aprotic solvents, but, as we have shown (ref. 8), this is not the case. In fact, isolated water molecules are very similar to monomeric methanol molecules as hydrogen-bond donors (ref. 16), so this is improbable on chemical grounds.

These results are in sharp contrast with those for trialkylphosphates, for which no infraredn.m.r. correlations were apparent (refs. 17-18).

\section{Trimethylphosphate $\left(\mathrm{Me}_{3} \mathrm{PO}_{4}\right)$}

Unfortunately for these studies, there are generally three prominent bands in the P-O stretch region for $\mathrm{Me}_{3} \mathrm{PO}_{4}$ and other phosphates. One of these, (x) in Fig. 3, is independent of solvent and can be ignored. The other two (a and $\underline{b}$ ) are assigned to two distinct conformers. Unfortunately, the equilibrium $\underline{\mathrm{a}} \rightleftharpoons \underline{\mathrm{b}}$ is solvent (and temperature) dependent, which severely limits our ability to interpret infrared spectra when mixed solvents are used. For pure solvents, if equal oscillator strengths are assumed, weighted mean values can be calculated. 


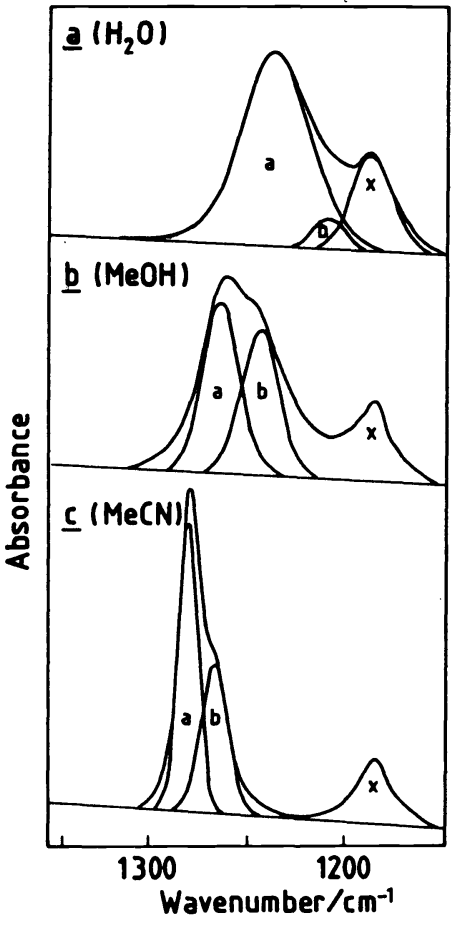

Fig. 3

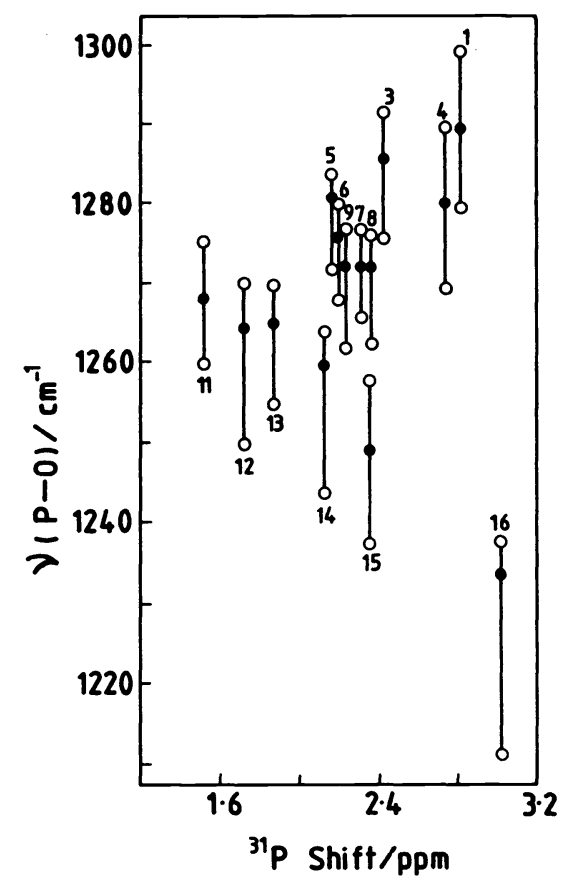

Fig. 4

Fig. 3. Infrared spectra for dilute solutions of $\mathrm{Me}_{3} \mathrm{PO}_{4}$ in a water, $\underline{b}$ methanol and $\subseteq$ cyancmethane in the $\mathrm{P}-\mathrm{O}$ stretch regions, showing features assigned to the high frequency conformer (a) and low frequency conformer (b). [Band (x) is discussed in the text.]

Fig. 4. Plot of ${ }^{31} \mathrm{P}$ resonance shifts versus (P-O) stretch frequency for $\mathrm{Me}_{3} \mathrm{PO}_{4}$ in dilute solutions in a range of pure solvents. [o values for the two infrared components, $\bullet$ weighted-mean values.]

KEY: 1. Cyclohexane, 2. Triethylamine, 3. Tetrachloromethane, 4. Tetrahydrofuran (THF), 5. Acetone, 6. Acetonitrile (MeCN), 7. Nitromethane, 8. Dimethylsulphoxide (DMSO), 9. Methylene chloride, 10. Trichloromethane, 11. Tert-Butanol, 12. Iso-Propanol, 13. Ethanol, 14. Methanol (MeOH), 15. Ethane-Diol (DIOL), 16. Water $\left(\mathrm{H}_{2} \mathrm{O}\right)$.

In Fig. 4, which demonstrates the complete absence of any correlation between the ${ }^{31} \mathrm{P}$ shifts and the infrared data, the central, filled symbols are the weighted mean results, and the open symbols are for the individual bands.

In fact, relative to $E t_{3} \mathrm{PO}$, the ${ }^{31} \mathrm{P}$ shifts are very small, and are clearly useless as a measure of solvation. I make no attempt to explain these shifts. On the other hand, the infrared shifts are quite extensive, and, despite the complication of two confonmers, can be used as a probe of solvation. There is a clear, qualitative dependance on the solvent acceptor number, but the trend for aprotic solvents follows a different line from that for protic solvents. The latter correlation is markedly curved, but becomes reasonably linear if allowance is made for the different solvation numbers for $\mathrm{Et}_{3} \mathrm{PO}$ and $\mathrm{Me}_{3} \mathrm{PO}_{4}$ (see below).

Since the ${ }^{31} \mathrm{P}$ shifts proved to be so unsatisfactory, ${ }^{17} \mathrm{O}$ shifts for the $\mathrm{P}-\mathrm{O}$ and MeO oxygens were also measured (ref. 18). Again, there were no clear trends for a range of solvents, and no correlations were found with the ${ }^{31} \mathrm{P}$ shifts or the infrared shifts. Clearly, $\mathrm{Me}_{3} \mathrm{PO}_{4}$, and indeed, other trialkylphosphates are poor solvent probes. Nevertheless, the results of mixed solvent studies (refs. 17-18) suggest that the monosolvate, (MeO) ${ }_{3} \mathrm{PO}---\mathrm{HOMe}$ dominates in methanolic solutions and the disolvate $(\mathrm{MeO})_{3} \mathrm{PO}---\left(\mathrm{H}_{2} \mathrm{O}\right)_{2}$ dominates in aqueous solutions. These results will be described fully elsewhere.

\section{Other phosphorus derivatives}

Some work has also been done on three related compounds, dimethyl methylphosphonate $(\mathrm{MeO})_{2} \mathrm{P}(\mathrm{O}) \mathrm{Me}$, the sulphur derivative, $(\mathrm{MeO})_{2} \mathrm{P}(\mathrm{O}) \mathrm{SMe}$, and the important solvent, hexamethylphosphoramide (HMPA). For the first two, two major conformers contribute, making infrared analysis difficult, whilst for HMPA another band severely interferes with the P-O stretch band for same solvents. 

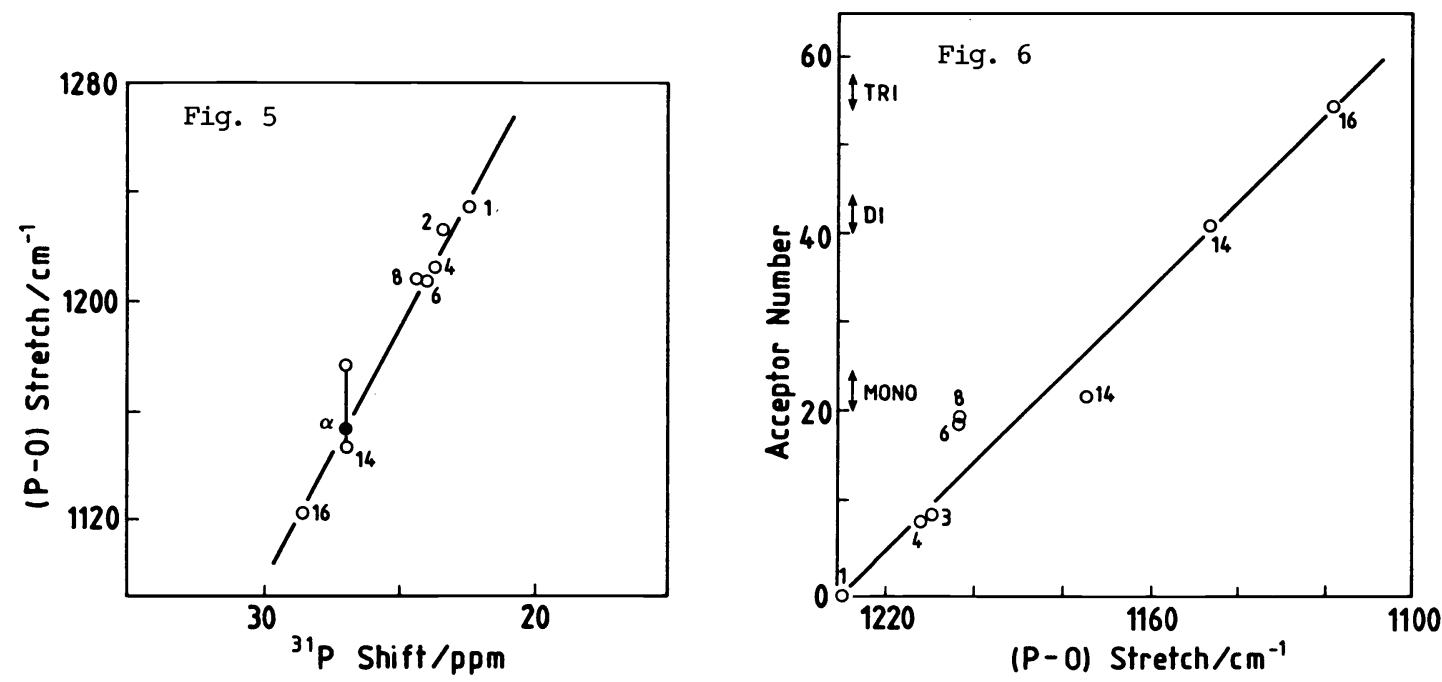

Fig. 5. Correlation between ${ }^{31} \mathrm{P}$ resonance shifts and $\nu(\mathrm{P}-\mathrm{O})$ for HMPA in dilute solution in a range of pure solvents ( $\alpha$ denotes the weighted-mean value for the infrared result). [Key as for Fig. 4.]

Fig. 6. Correlation between $\nu(\mathrm{P}-0)$ for HMPA and solvent acceptor numbers. [Key as for Fig. 4.]

However, in all three cases, the ${ }^{31} \mathrm{P}$ shifts are much larger than those for $\mathrm{Me}_{3} \mathrm{PO}_{4}$, and are found to correlate quite well with the infrared shifts, despite these complications. An example is given in Fig. 5, for HMPA. As with $E t_{3} P O$, solutions of HMPA in methanol gave two distinct $\mathrm{P}-\mathrm{O}$ stretch bands, the weighted mean of which $(\underline{\alpha})$ correlates well with the ${ }^{31} \mathrm{P}$ shift. For HMPA, the correlation with solvent acceptor numbers is quite good, which underlines the similarity between $\mathrm{Et}_{3} \mathrm{PO}$ and $\left(\mathrm{Me}_{2} \mathrm{~N}\right)_{3} \mathrm{PO}(\mathrm{Fig} .6)$.

There is no doubt that $\mathrm{Et}_{3} \mathrm{PO}$ is the best phosphorus probe amongst these campounds. I now turn to some carbonyl-containing compounds, of which acetone has been most widely studied (refs. 19-23). As with $\mathrm{Et}_{3} \mathrm{PO}$, our own work has centred on the combined use of infrared (C-O stretch) and n.m.r. $\left({ }^{13} \mathrm{C}\right)$, a good correlation being obtained (ref. 9) (Fig. 7). Once

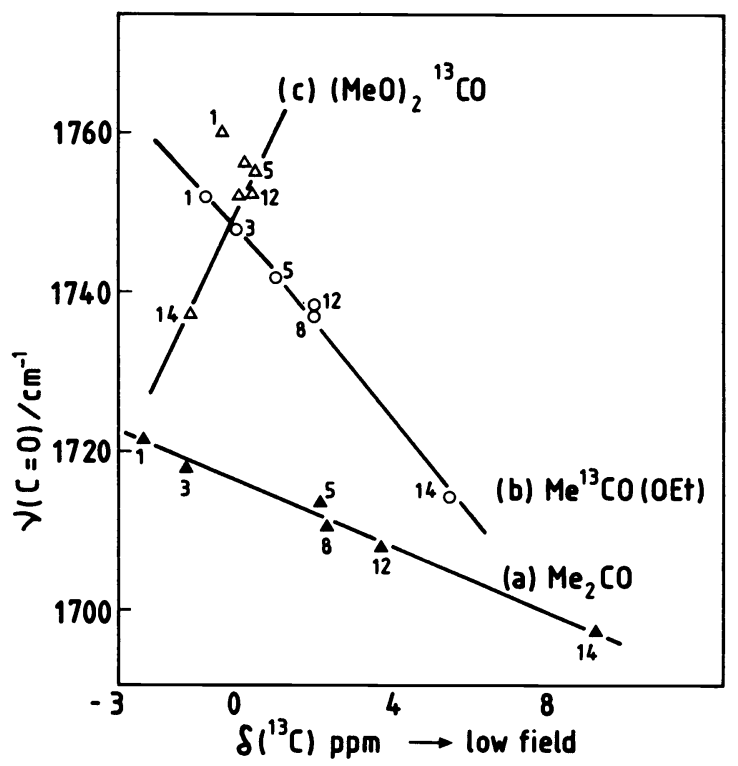

Fig. 7. Correlations between $\nu(\mathrm{C}=0)$ and ${ }^{13} \mathrm{C}$ shifts for (a) $\mathrm{Me}_{2}{ }^{13} \mathrm{CO}$, (b) $\mathrm{Me}^{\mathrm{i} 3} \mathrm{CO}(\mathrm{OEt})$ and (c) $(\mathrm{MeO})_{2}{ }^{13} \mathrm{CO}$. Curve (c) has been arbitrarily drawn and is not thought to have any specific significance other than to highlight the lack of sensitivity of the ${ }^{13} \mathrm{C}$ resonance for $(\mathrm{MeO})_{2} \mathrm{CO}$.

KEY: 1. Hexane, 2. $\mathrm{Et}_{3} \mathrm{~N}, 3 . \mathrm{CCl}_{4}, 4 . \mathrm{THF}, 5 . \mathrm{MeCN}, 6 . \mathrm{HMPA}, 7 . \mathrm{Bu}^{\mathrm{t}} \mathrm{OH}$,

8. $\mathrm{CDCl}_{3}$, 9. $\mathrm{MeNO}_{2}$, 10. DMSO, 11. EtOH, 12. MeOH, 13. ethanediol, 14. $\mathrm{D}_{2} \mathrm{O}$. 


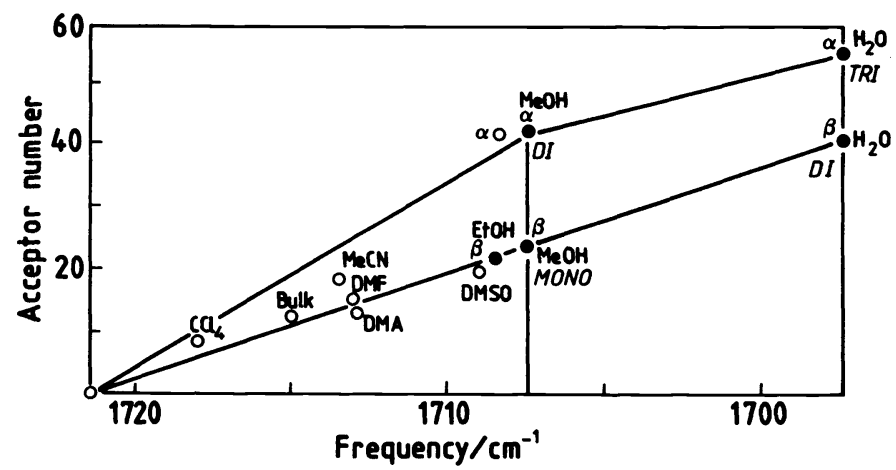

Fig. 8. Correlation between the $\nu_{\text {co }}$ values for acetone in a range of pure solvents and their acceptor numbers. The points marked $\underline{\alpha}$ use the correct acceptor number for $\mathrm{MeOH}$ and $\mathrm{H}_{2} \mathrm{O}$, whilst those marked $\underline{\beta}$ are for monohydrogen-bonded $\mathrm{Et}_{3} \mathrm{PO}$ in $\mathrm{MeOH}$ and for dihydrogen-bonded $\mathrm{Et}_{3} \mathrm{PO}$ in $\mathrm{H}_{2} \mathrm{O}$.

again, two C-O stretch bands were obtained for the alcohols, and points ( $\underline{\alpha})$ are the weighted-mean values.

There is again a reasonable correlation with solvent acceptor numbers (Fig. 8). When the true acceptor numbers are used, the results for water and for the main feature for the alcohols are poorly correlated with the remainder. However, when allowance is made for the change in solvation numbers on going from $\mathrm{Et}_{3} \mathrm{PO}$ to acetone, the lower line in Fig. 8 is obtained, giving a greatly improved correlation. As I try to establish in Section $\mathrm{B}, \mathrm{Et}_{3} \mathrm{PO}$ is largely tri-solvated in water, whereas $\mathrm{Me}_{2} \mathrm{CO}$ is disolvated. Hence we use a value for $\mathrm{Et}_{3} \mathrm{PO}$ corresponding to a disolvate in this improved correlation. Similarly, Et ${ }_{3} \mathrm{PO}$ is largely disolvated in $\mathrm{MeOH}$, but $\mathrm{Me}_{2} \mathrm{CO}$ is largely mono-solvated, so a mono-solvate value is used. In general, this approach has proven to give greatly improved correlations for protic solvents, but it can only be used if the solvation number of the solvent is known. [By solvation number, in this context, I mean the number of hydrogen bonds formed by the probe with protic solvents.]

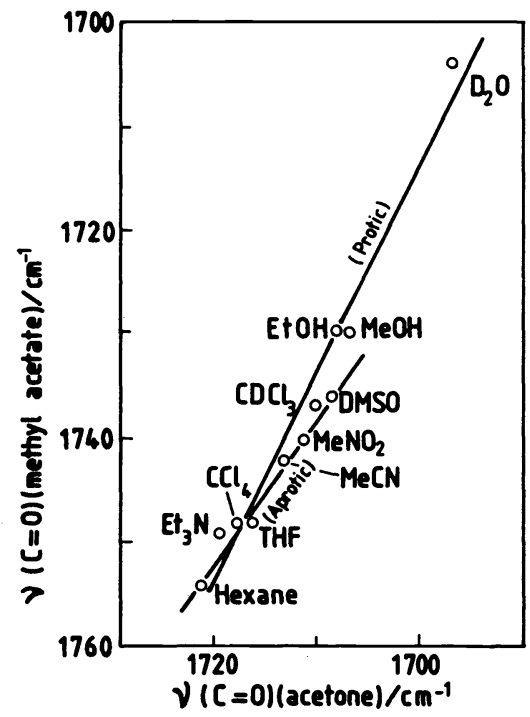

Fig. 9. Correlation between $\nu(C=0)$ for methylacetate and for acetone in a range of solvents. The trend for dimethyl carbonate was similar. [When two bands were present, only the most intense was used.]

\section{Esters and carbonates}

In our work, attention was largely centred on methyl acetate MeCO(OMe), and dimethyl carbonate (MeO) ${ }_{2} \mathrm{CO}$ (ref. 11). Other studies of esters in various solvents are given in refs. 24-31. Fortunately in these cases, although cis and trans conformers are present, only the former contributes significantly to the spectra. The $\mathrm{C}-\mathrm{O}$ band for both methylacetate and dimethyl carbonate in pure solvents correlate reasonably well with the corresponding bands for acetone (Fig. 9), although the shifts are almost three times larger for the ester than for acetone. However, the esters are clearly weaker bases than acetone, as evidenced, for example, by the greater concentration of non hydrogen-bonded ester in $\mathrm{MeOH}$, and the clear presence of mono- and di-solvated species in water for the esters, whereas only the disolvate is detected for aqueous acetone. In fact, in all our studies of this type, the esters are the only compounds that exhibit a variable solvation number in water, in marked contrast with the alcohols, which almost always give at least two detectable solvates. 
For the acetate, the ${ }^{13} \mathrm{C}(\mathrm{CO})$ shifts correlate reasonably well with $\nu(\mathrm{CO})$ provided weightedmean values are used for the infrared spectra. However, in contrast with the infrared sensitivity, the ${ }^{13} \mathrm{C}$ sensitivity is reduced for the esters, and is almost lost for the carbonates (Fig. 7). This behaviour parallels that of the phosphate derivatives and suggests that there must be a common origin for the lack of n.m.r. sensitivity for $\mathrm{Me}_{3} \mathrm{PO}_{4}$ and $\mathrm{Me}_{2} \mathrm{CO}_{3}$ (see below).

We also studied the C-OMe stretching frequencies, which were found to correlate inversely with that for the $\mathrm{C}=\mathrm{O}$ group. This result suggests strongly that hydrogen-bonding at the $\mathrm{C}=\mathrm{O}$ oxygen is the cause of the $\mathrm{C}-\mathrm{OMe}$ shift, and not solvation at the ester oxygen. This conclusion accords with those of others who have studied this issue (refs. 21-23).

The same selectivity apparently applies to amides.

\section{Dialkyl amides}

We have made an extensive study of a range of amides, but here I only discuss the dimethyl derivatives of formamide (DMF) and acetamide (DMA). [When $\mathrm{N}-\mathrm{H}$ groups are present, they actively participate in solvation processes, so for a proper study, it is necessary to monitor these groups as well as the $\mathrm{C}=0$ group. These results will, hopefully, be presented in the near future (ref. 32).]

For both DMF and DMA, well-defined $C=0$ stretch bands are found, which are very sensitive to solvation. Also, the ${ }^{13} \mathrm{C}(\mathrm{CO})$ resonance is sensitive, and the expected linear correlation is found (Fig. 10). As in the other correlations, point $\alpha$ is an average for the two methanol bands. This plot is for DMA; that for DMF was similar, except that the infrared sensitivity is reduced. Hence, most attention has been given to DMA. Apart from results for $\mathrm{MeCN}$ and $\left(\mathrm{CF}_{3}\right)_{2} \mathrm{CHOH}$, these correlations are good.

We conclude that both amides are good probes, and that mixed solvent results should be readily interpreted (see Section $B$ ).

As expected, these results correlate well with acceptor numbers, provided adjustment of the acceptor numbers is made to suit a di-solvate for water, and a mono-solvate and di-solvate in methanol (Fig. 11) (see below). There is no need to draw separate lines for the protic and aprotic solvents in these cases.
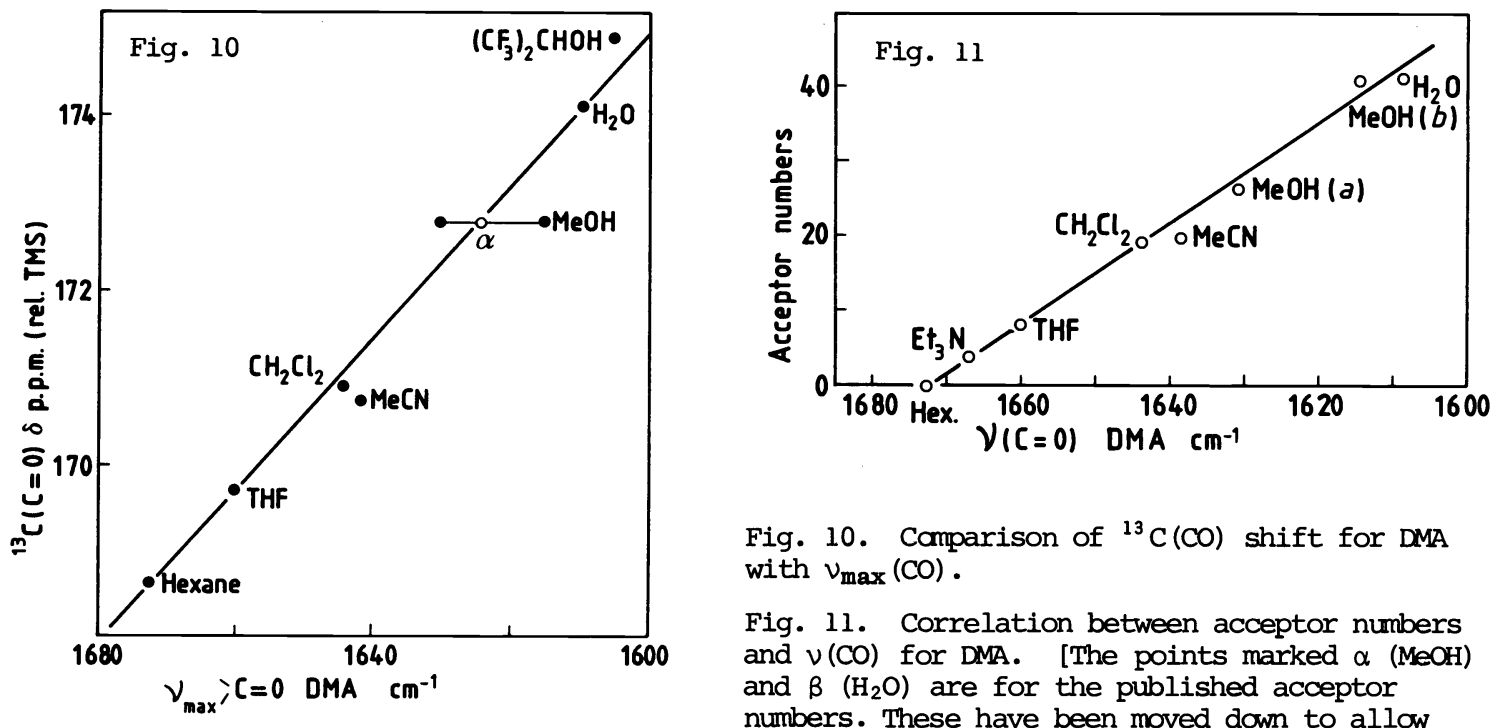

Fig. 10. Comparison of ${ }^{13} \mathrm{C}(\mathrm{CO})$ shift for DMA with $\nu_{\max }(\mathrm{CO})$.

Fig. 11. Correlation between acceptor numbers and $v(\mathrm{CO})$ for DMA. [The points marked $\alpha$ (MeOH) and $\beta\left(\mathrm{H}_{2} \mathrm{O}\right)$ are for the published acceptor numbers. These have been moved down to allow for the changes in solvation numbers on going fram $\mathrm{Et}_{3} \mathrm{PO}$ to DMA.]

\section{Dialkyl nitroxides}

Because they are paramagnetic, and give well-resolved e.s.r. spectra, these compounds have been used widely as probes of their environment. Indeed, they are of major importance as 'spin-probes' in biological studies. However, the e.s.r. technique is like n.m.r. in giving, generally, time-averaged spectra, and hence interpretation is often ambiguous. Some time ago we studied $\left(\mathrm{Me}_{3} \mathrm{C}\right)_{2} \mathrm{NO}$ in a range of pure and mixed solvents, concentrating mainly on the hyperfine coupling $A\left({ }^{14} \mathrm{~N}\right)$, since this correlated well with the line-width variations, in most systems (refs. 14-15). Again, interpretation was ambiguous: for example, $\Delta A\left({ }^{14} \mathrm{~N}\right)$ was much greater for aqueous than for methanolic solutions, but there was no way of deciding why this should be the case. 
We therefore turned to infrared spectroscopy in the hope of obtaining answers to such questions (ref. 10). Unfortunately, despite their structural similarity, the $\mathrm{N}-\mathrm{O}$ stretch is very weak compared with the C-O stretch for ketones, and also both this, and the corresponding resonance Raman band proved to be relatively insensitive to solvent changes. Fortunately, the intense $\sigma-\pi$ optical band was more sensitive and more readily monitored. There is a good correlation between $\mathrm{A}\left({ }^{14} \mathrm{~N}\right)$ and $\nu_{\max }$, so that the optical results could be used to interpret the e.s.r. parameters. As indicated in Section B, this work has enabled us to reconstruct the e.s.r. curves, and to answer the questions posed above.

\section{Cyanoalkanes}

Since cyanomethane, MeCN, is one of the most widely used non-aqueous solvents, as well as being used extensively in binary aqueous systems, it seemed worthwhile to endeavour to use it as a probe, in the hope of understanding more about its modes of solvation. Although infrared, ${ }^{13} \mathrm{C}$ and ${ }^{14} \mathrm{~N}$ n.m.r. methods have been used widely in studying the modes of interaction between MeCN and metal cations, little direct solvation work has been undertaken.

In fact, $\nu(C \equiv N)$ is not very sensitive to solvent changes for the usual group of solvents. However, in contrast with most of the probes used, there are very large changes in the extinction coefficients for different solvents, the minimum being that for solutions in hexane, with rapid increases as the solvation of MeCN increases (Fig. 12). These results are particularly striking in that the shifts are clearly divided into two sets, strongly interacting aprotic solvents such as DMSO causing low-frequency shifts, as in all cases reported above, but the protic solvents causing high frequency shifts, which is a unique result (Fig. 12).

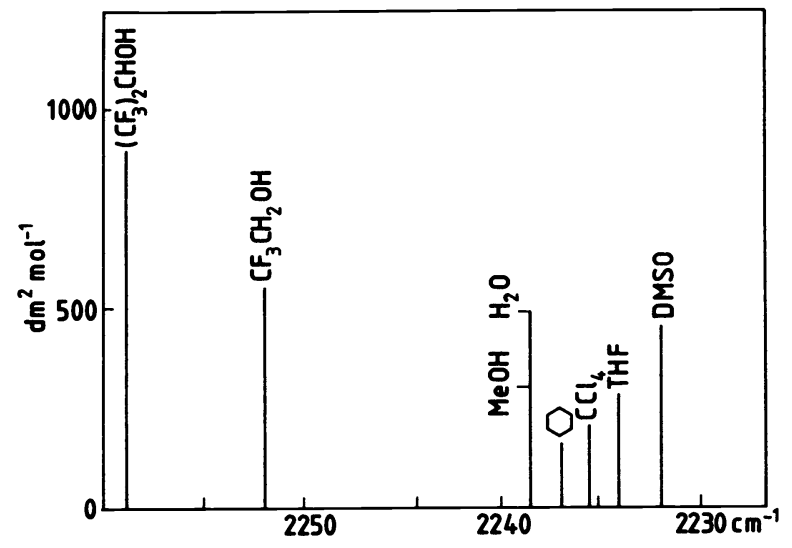

Fig. 12. Changes in absorbance with frequency for MeCN in a range of solvents.

Qualitatively, the reason for this difference can be understood in terms of the two limiting structures (1) and (2). In both cases, excitation apparently causes an increase in the<smiles>Cc1n[R5](C)(C)o1</smiles>

(1)<smiles>[R]O[N+]#CC</smiles>

(2)

group dipole, but the $\pi$ interaction (1) weakens the overall $\mathrm{C}-\mathrm{N}$ bonding, whereas the $\sigma-$ interaction (2) appears to strengthen this bonding (unless the effect is a 'classical' blocking of the vibrational mode by the solvent molecule) .

These results clearly cannot be accommodated by acceptor numbers. A plot for the aprotic solvents is linear with considerable scatter, but for the protic solvents there is no correlation, the shifts for the fluorinated alcohols being far larger than predicted.

Mixed solvent studies have been undertaken, but are rendered difficult to interpret because of the large intensity changes (ref. 33). However, they strongly suggest that the solvation number for MeCN in water is only one, whilst in methanol, only ca. $30 \%$ of the molecules form hydrogen bonds.

\section{Other probes}

Preliminary work has been carried out for various other probes, including $\mathrm{MeNO}_{2}$ and $\mathrm{DMSO}$ The latter is very sensitive in the $\mathrm{S}-\mathrm{O}$ stretch region and gives good mixed solvent results (ref. 34). 


\section{B. PROTIC-APROTIC BINARY SYSTEMS}

In this section I illustrate the information that can be gleaned from the infrared spectra of probe molecules in mixed solvent systems and show how the results can be analysed in terms of specific species which are gained and lost, as well as in terms of shifts.

Results for $\mathrm{Et}_{3} \mathrm{PO}$ are typical, but more complex than for other probes because of the high solvation numbers. Considering the solvent system $\mathrm{H}_{2} \mathrm{O}+\mathrm{MeCN}$ (Fig. 13), there can be no doubt that there are four distinct species of $\mathrm{Et}_{3} \mathrm{PO}$ involved. These are indicated by the arrows marked $(0),(1),(2)$ and (3). There are clear shifts in these components as the composition changes, especially for band (2) which shifts strongly to high frequencies as the [MeCN] increases. However, that there are distinct species involved is clearly shown by curves such as $5(3+2), 9(2+1)$ and $10(1+0)$, which show two distinct maxima. In same of our other studies, resolution is less good, and computer analysis is a necessity: however, we are confident in these analyses because the results tie in so well with those in which resolution is clear.

Using computer analysis, these curves can be resolved into individual components, as shown in Fig. $13(\mathrm{~b})$, which tells us the composition of each solution, in terms of the concentrations of the four distinct solvates.

These results can then be used to explain the ${ }^{31} \mathrm{P}$ shifts as shown in Fig. 13(c) for the systems $\mathrm{H}_{2} \mathrm{O}+\mathrm{MeCN}, \mathrm{H}_{2} \mathrm{O}+\mathrm{THF}$ and $\mathrm{H}_{2} \mathrm{O}+$ DMSO. The smooth curves are the experimental results and the points are those deduced from the infrared results. I stress that sets of

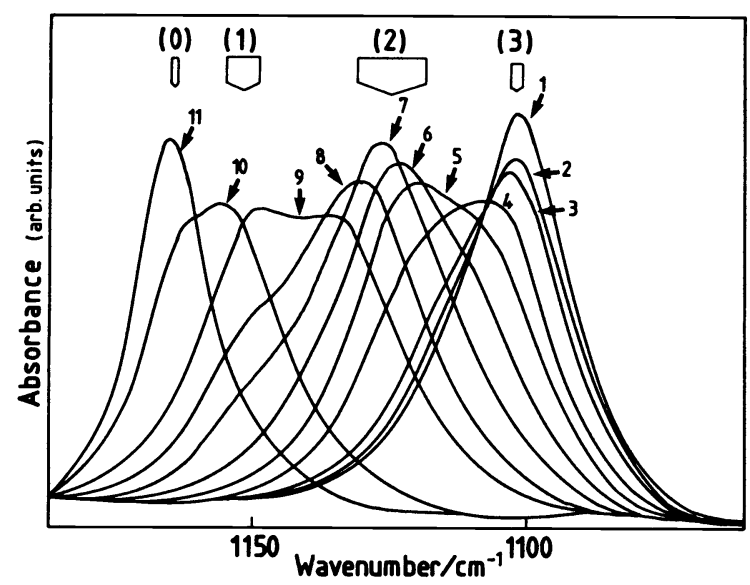

Fig. $13(a)$

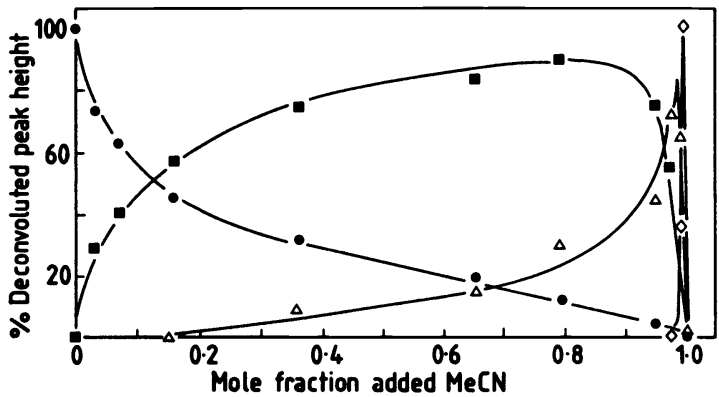

Fig. 13(b)

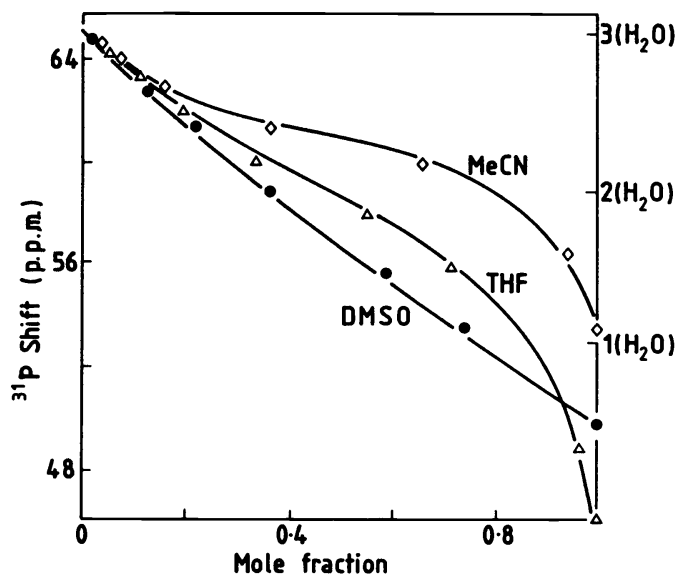

Fig. $13(c)$

Fig. 13(a). Infrared spectra for $\mathrm{Et}_{3} \mathrm{PO}$ in a range of $\mathrm{H}_{2} \mathrm{O}+\mathrm{MeCN}$ solvents. $\mathrm{KEY}$ (in mole fraction MeCN): $1=0.00,2=0.03,3=0.07,4=0.16,5=0.36$, $6=0.65,7=0.79,8=0.95,9=0.97,10=0.99,11=1.00$. [Band maxima are indicated by broad arrows which span their shifts, the numbers indicating the postulated number of water molecules.

Fig. 13(b) . Trends in band intensities for $\mathrm{Et}_{3} \mathrm{PO}$ in a range of $\mathrm{H}_{2} \mathrm{O}+\mathrm{MeCN}$ solvents; - trihydrate, $\square$ dihydrate, $\Delta$ monohydrate, $\diamond$ non-hydrated.

Fig. 13(c). Plot of ${ }^{31} \mathrm{P}$ shift of aqueous $\mathrm{Et}_{3} \mathrm{PO}$ on addition of various basic cosolvents. [ $\Delta, \diamond$ and $\bullet$ indicate experimental points; continuous lines indicate reconstructed curves from infrared data.] 
shifts such as those in Fig. 13(c) can, because of rapid averaging, be interpreted in many ways in the absence of further information. In our view, the infrared results make the interpretation unambiguous.

Thus, two important consequences of these studies are that "solvation numbers" (i.e. the number of hydrogen-bonds) can be estimated, and trends in n.m.r. shifts can be explained. Another is that for a given protic solvent, the effect of varying the aprotic component in binary systems containing a probe can be understood. Compare, for example, the three systems, $\mathrm{MeOH}+\mathrm{MeCN}$ (a), $\mathrm{MeOH}+\mathrm{THF}$ (b) and $\mathrm{MeOH}+\mathrm{DMSO}$ (c) in Fig. 14. The order of increasing 'basicity', MeCN < THF <DMSO is clearly manifested by, for example, the shifts in the $50 \%$ crossover points. When less basic probes are used, competition is, of course, less marked. The secondary solvent shifts of each band make these analyses less accurate, but are themselves informative, and can be used to refine the fit to the n.m.r. data.
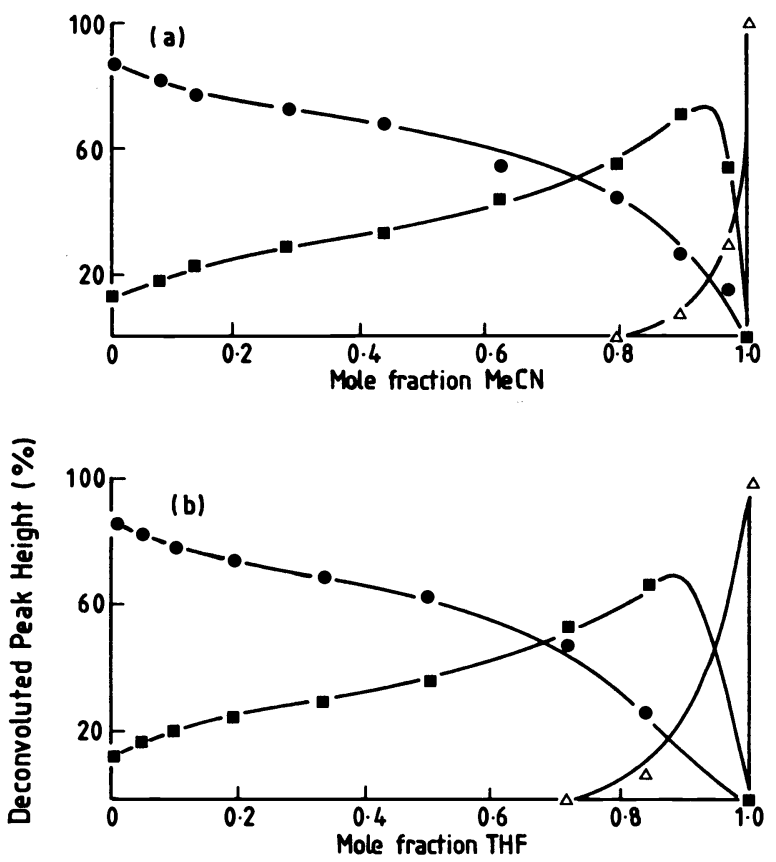

Fig. 14. Trends in the intensities of the deconvoluted $\nu(\mathrm{P}-\mathrm{O})$ bands for individual solvates in mixed methanolic systems. - $2 \mathrm{MeOH} ; \mathbf{a}, 1 \mathrm{MeOH} ; \Delta, 0 \mathrm{MeOH}$.
(a) $\mathrm{MeOH}+\mathrm{MeCN}$,
(b) $\mathrm{MeOH}+\mathrm{THF}$,
(c) $\mathrm{MeOH}+\mathrm{DMSO}$.

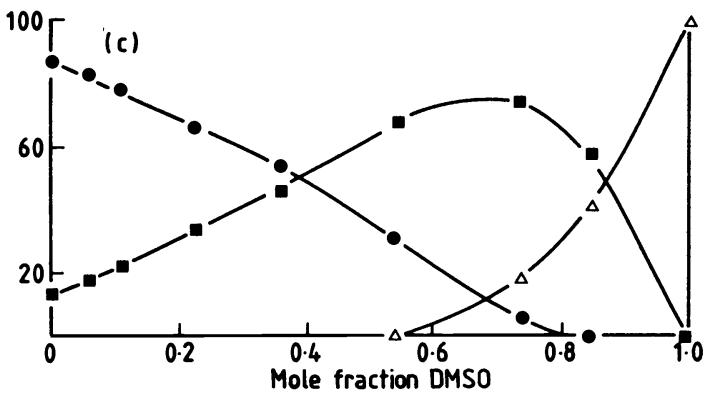

For the hydrogen-bonded solvates, the shifts are to high frequency, and can be ascribed to removal of secondary protic solvation by the aprotic solvent, which reduces the strength of the bond (s) to the probe molecules. However, in same cases, the band due to non hydrogenbonded molecules shifts back to low frequency as the aprotic component is added. This indicates that the non hydrogen-bonded probe molecules are 'freer' in the protic solvent environment than in same pure aprotic media, such as DMSO.

However, all our attempts to detect specific probe-aprotic solvent units (such as (l), for example) have failed. All systems that might have been expected to give defined species have only shown steady shifts to the final, pure solvent values. Thus either structures are never sufficiently defined, or interchange between different relative orientations and solvent exchanges are too fast on the vibrational time-scale and averaged information results. 
The results are difficult to express in tabular form, but I give same salient factors in the Table.

Table showing relative amounts of protic solvation states for various probes. Also relative points of solvated state crossovers during a mixed solvent system versus mole fraction.

\begin{tabular}{|c|c|c|c|c|c|c|c|c|c|c|c|c|}
\hline \multirow[t]{2}{*}{ Probe } & \multirow[t]{2}{*}{$\mathrm{DN}$} & \multicolumn{8}{|c|}{$\begin{array}{l}\text { Solvation Number } \\
\text { ( } 8 \text { of mols in various states) } \\
\begin{array}{l|l}\mathrm{H}_{2} \mathrm{O} & \mathrm{MeOH} \\
\end{array}\end{array}$} & \multicolumn{3}{|c|}{$\begin{array}{l}\text { Crossover Points } \\
\text { (mol fraction) } \\
\mathrm{H}_{2} \mathrm{O} \rightarrow \mathrm{MeCN} \\
\end{array}$} \\
\hline & & 3 & 2 & 1 & 0 & 3 & 2 & 1 & 0 & $3 / 2$ & $2 / 1$ & $1 / 0$ \\
\hline $\begin{array}{l}\mathrm{Et}_{3} \mathrm{PO} \\
\mathrm{HMPA} \\
(\mathrm{MeO})_{2} \mathrm{MePO} \\
(\mathrm{MeO})_{3} \mathrm{PO}\end{array}$ & $\begin{array}{l}40.0 \\
38.8 \\
23.0\end{array}$ & $\begin{array}{l}100 \\
100 \\
100 \\
-\end{array}$ & $\begin{array}{c}- \\
\overline{1} \\
\overline{100}\end{array}$ & $\begin{array}{l}- \\
- \\
-\end{array}$ & $\begin{array}{l}- \\
- \\
-\end{array}$ & $\begin{array}{l}- \\
- \\
-\end{array}$ & $\begin{array}{r}85 \\
60 \\
25 \\
-\end{array}$ & $\begin{array}{l}25 \\
40 \\
60 \\
45\end{array}$ & $\begin{array}{c}- \\
- \\
15 \\
55\end{array}$ & 0.13 & $\begin{array}{l}0.65 \\
0.65\end{array}$ & $\begin{array}{l}0.98 \\
0.95 \\
0.90\end{array}$ \\
\hline $\begin{array}{l}\text { DMA } \\
\text { DMF } \\
\text { NMA } \\
\text { NMF }\end{array}$ & $\begin{array}{l}27.8 \\
26.6\end{array}$ & $\begin{array}{l}- \\
- \\
-\end{array}$ & $\begin{array}{l}100 \\
100 \\
100 \\
100\end{array}$ & $\begin{array}{l}- \\
- \\
-\end{array}$ & $\begin{array}{l}- \\
- \\
-\end{array}$ & $\begin{array}{l}- \\
- \\
-\end{array}$ & $\begin{array}{l}40 \\
20 \\
47 \\
10\end{array}$ & $\begin{array}{l}60 \\
80 \\
53 \\
90\end{array}$ & $\begin{array}{l}- \\
- \\
-\end{array}$ & - & $\underline{0.65}$ & 0.95 \\
\hline $\begin{array}{l}\mathrm{Me}_{2} \mathrm{CO} \\
\mathrm{MeCOOMe} \\
(\mathrm{MeO})_{2} \mathrm{CO}\end{array}$ & $\begin{array}{l}17.0 \\
16.5\end{array}$ & - & $\begin{array}{r}100 \\
50 \\
30\end{array}$ & $\begin{array}{l}- \\
50 \\
70\end{array}$ & $\begin{array}{l}- \\
-\end{array}$ & $\begin{array}{l}- \\
-\end{array}$ & $\begin{array}{l}- \\
-\end{array}$ & $\begin{array}{l}90 \\
50 \\
35\end{array}$ & $\begin{array}{l}10 \\
50 \\
65\end{array}$ & & 0.25 & $\begin{array}{l}0.80 \\
0.60 \\
0.60\end{array}$ \\
\hline $\begin{array}{l}\text { MeCN } \\
\text { tBuCN }\end{array}$ & 14.1 & - & - & $\begin{array}{l}100 \\
100\end{array}$ & - & - & - & $\begin{array}{l}30 \\
30\end{array}$ & $\begin{array}{l}70 \\
70\end{array}$ & & & \\
\hline
\end{tabular}

\section{PROTIC + PROTIC SOLVENT SYSTEMS}

In all cases, we have studied $\mathrm{H}_{2} \mathrm{O}+\mathrm{MeOH}$ solvent systems, the results being in good accord with expectation. The major problem is that we cannot clearly distinguish between mono-aquo probes, and those bonded to one MeOH molecule. Thus for acetone, we can follow the loss of the dihydrate and the gain of a mono-solvate and finally some non-bonded acetone, but we cannot follow the switch fram $\mathrm{Me}_{2} \mathrm{CO}---\mathrm{HOH}$ to $\mathrm{Me}_{2} \mathrm{CO}---\mathrm{HOMe}$ units (Fig. 15).

\section{CONCLUSIONS AND COMMENTS}

I hope that I have established the utility of this method of studying binary solutions. There is more to be done, and more to be extracted fram the present data. The results should prove to be useful in testing the efficacy of computer simulation studies of such systems.

Some extra comments are required on same aspects of the results. I finish with a brief consideration of the changes in n.m.r. shift sensitivities; on the curious ability of water to bring out the maximum solvation number of molecules; and, finally, on the possible rôle of hydrophobic interactions.

\section{Sensitivity of n.m.r. shifts}

The contrast between the high n.m.r. shift sensitivity of $\mathrm{Et}_{3} \mathrm{PO}$ and zero effective sensitivity to solvation changes for $(\mathrm{MeO})_{3} \mathrm{PO}$ is very striking. The same applies to the high sensitivity of the ${ }^{13} \mathrm{C}$ resonance (CO) for $\mathrm{Me}_{2} \mathrm{CO}$ and near absence for (MeO) ${ }_{2} \mathrm{CO}$. In both cases it is probable that the explanation lies in the presence or absence of low-lying magnetically coupled excited states. It is significant that (MeO) ${ }_{3} \mathrm{PO}$ and $(\mathrm{MeO})_{2} \mathrm{CO}$ have no absorption bands below ca. $50,000 \mathrm{~cm}^{-1}$, in marked contrast with $\mathrm{Et}_{3} \mathrm{PO}$ and $\mathrm{Me}_{2} \mathrm{CO}$.

\section{High solvation numbers in aqueous solutions}

These results (Table) leave no doubt that the solvation numbers shown by aprotic probes in water are greater than in any other solvent so far tested. In particular, they are greater than those for corresponding solutions in methanol, despite the similarity in protondonating tendencies for these two molecules. Indeed, when a cosolvent is added to water to reduce the solvation number to that of methanol, the shifts are almost identical.

One simple explanation is steric, but in my view this is unlikely, since fully hydrogenbonded water molecules (i.e. with four bonds) are, in effect, quite as bulky as methanol. I 
think the explanation lies in the presence of large concentrations (5-10\%) of (OH) free groups in liquid water, which are absent in liquid methanol at ambient temperatures (refs. 6-7). This claim is debatable and I have attempted to support it in depth elsewhere (ref. 35): if, for the present, it is accepted, then it is clear that any site for bonding will be

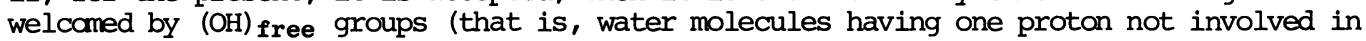
bonding), even if the resulting bond is weak. There is, of course, competition between forming an extra bond to a basic cosolvent and to the corresponding water molecules having one vacant oxygen site, which we label (lone-pair) free. Given that the intensely crosslinked and intertwined nature of the bonding in water prevents reaction with a certain number of such groups, then reaction with the cosolvent is still favourable. We have shown spectroscopically that $(\mathrm{OH})$ free groups do appear to be scavenged by basic aprotic cosolvents (refs. $6,7,36)$, so this argument is supported. However, two campounds are difficult to accamodate, in that different experiments appear to give conflicting results. One is MeCN and the other, HMPA.

The former cames out clearly as being mono-basic, even in water, as judged by the probe results (Fig. 12) (ref. 33). However, when we compare the trends shown in Fig. 13 (c), we would have expected that MeCN would, as a mono-base, be only half as effective as DMSO, which behaves as a di-base in water. The results suggest that the two solvents behave equally efficiently!

For HMPA, the probe studies suggest a solvation number of 3 in water, but other studies, including overtone work on the loss of $(\mathrm{OH})$ free groups, suggest that values of 4-5 are better. These and other anomalies require further study.

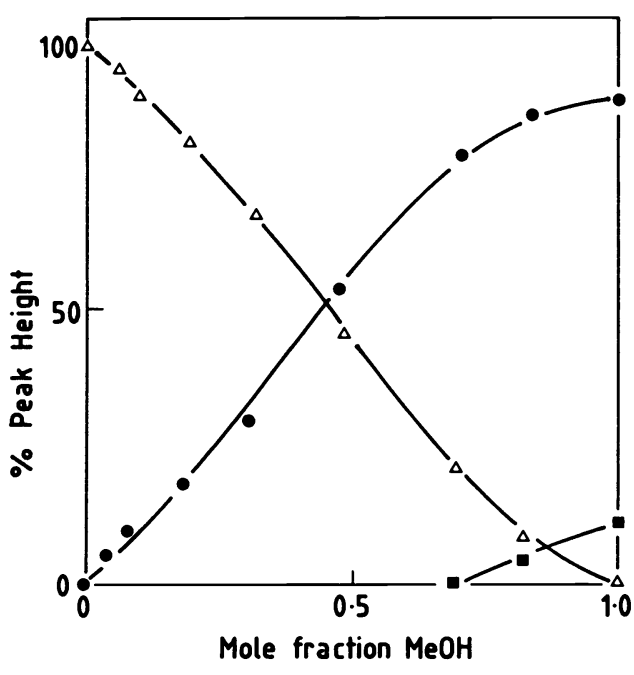

Fig. 15

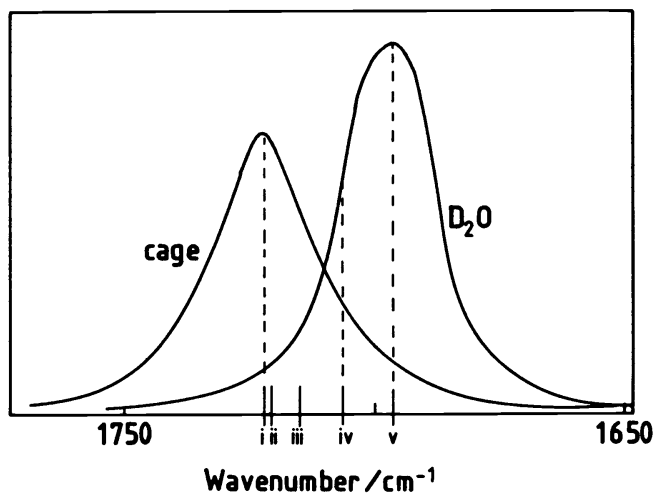

Fig. 16

Fig. 15. Trends for the concentrations of the dihydrate $(\Delta)$, the monohydrate and the methanol (৩) solvate and non-hydrogen-bonded acetone ( $(\boldsymbol{a})$ for solutions of acetone in $\mathrm{H}_{2} \mathrm{O}+\mathrm{MeOH}$.

Fig. 16. Infrared spectra ( $\mathrm{C}=0$ stretch) for acetone in water $(0.05$ mole fraction acetone) (a) at $0^{\circ} \mathrm{C}$, (b) at $-30^{\circ} \mathrm{C}$ on storage for $7 \mathrm{~h}$. Band maxima for acetone in (i) clathrate cage, (ii) hexane, (iii) bulk acetone, (iv) concentrated and (v) dilute aqueous solutions are given as vertical bars.

\section{Hydrophobic effects}

I have spent same time comparing water and methanol, but have ignored one major difference, between these solvents, namely the tendency for water to accommodate "hydrophobic" groups by surrounding them with hydrogen-bonded 'cages' such as are found in solid clathrates. It may well be that incipient cages do form around the alkyl groups of $\mathrm{Et}_{3} \mathrm{PO}$ and $\left(\mathrm{Me}_{3} \mathrm{C}\right)_{2} \mathrm{NO}$, for example. However, this does not directly affect the property that we are concerned with, namely hydrogen bonding to the basic oxygen ligands. It is interesting to note that acetone in its clathrate compound with water has a completely distinct $\mathrm{C}-\mathrm{O}$ absorption from that for aqueous solutions (Fig. 16) (ref. 37). In the clathrate the acetone molecules are 'free', but in the liquid they are strongly hydrogen-bonded. Thus, in this case at least, it seems that the important factor is the (di) solvation at oxygen rather than clathrate cage formation in fluid solutions. 


\section{Acknowledgement}

I am most grateful to Dr. Graham Eaton for his extensive help throughout these studies, to the various research students mentioned in the references, and to Miss $V$. Orson-Wright for her preparation of the typescript.

\section{REFERENCES}

1. This article is taken as Solvation Spectra, Part 79.

2. M.J. Blandamer and M.F. Fox, Chem. Rev., 70, 59 (1970) .

3. M.C.R. Symons in Electron-Solvent and Anion-Solvent Interactions (eds. L. Kevan and B. Walker), p.31l, Elsevier/Amsterdam (1976).

4. M.C.R. Symons, pure \& Appl. Chem. , 49, 13 (1977) .

5. M.C.R. Symons, Pure \& Appl. Chem., 51, 1671 (1979) .

6. M.C.R. Symons, Phil. Trans. Roy. Soc. Lond. B, 272, 13 (1975).

7. M.C.R. Symons, ACC. Chem. Res., 14, 179 (1981).

8. M.C.R. Symons and G. Eaton, J. Chem. Soc., Faraday Trans. I, 78, 3033 (1982).

9. M.C.R. Symons and G. Eaton, J. Chem. Soc., Faraday Trans. I, 81, 1963 (1985).

10. M.C.R. Symons and A.S. Pena-Nuñez, J. Chem. Soc. Faraday Trans. I, 81, 2421 (1985).

11. K.B. Patel, G. Eaton and M.C.R. Symons, J. Chem. Soc., Faraday Trans. I, 81, 2775 (1985).

12. V. Gutmann, The Donor-Acceptor Approach to Molecular Interactions, Plenum Press, New York (1978)

13. C. Jolicoeur and H.L. Friedman, J. Soln. Chem., 3, 15 (1974).

14. Y.Y. Lim, E.A. Smith and M.C.R. Symons, J. Chem. Soc., Faraday Trans. I, 72, 2876 (1976).

15. S.E. Jackson, E.A. Smith and M.C.R. Symons, Discuss. Faraday Soc., 64, 174 (1978).

16. M.C.R. Symons, T.A. Shippey and P.P. Rastogi, J. Chem. Soc., Faraday Trans. I, 76,2251 (1980) .

17. K.B. Patel, Ph.D. Thesis, University of Leicester (1985) .

18. K.B. Patel, G. Eaton and M.C.R. Symons, J. Chem. Soc., Faraday Trans. I, to be submitted.

19. J. Lascamb, Ph.D. Thesis, University of Bordeaux (1960); L.J. Bellamy and R.J. Pace, Spectrochim. Acta, 19, 1831 (1963).

20. D.N. Glew, D.H. Mak and N.S. Rath, J. Chem. Soc., Chem. Commun., 264 (1968).

21. E.V. Goldammer and H.G. Hertz, J. Phys. Chem., 74, 3734 (1970).

22. M.J. Blandamer in Water: A Comprehensive Treatise (ed. F. Franks), vol. 2, p.488, Plenum Press, New York (1973).

23. M.F. Fox, J. Chem. Soc., Faraday Trans. I, 68, 1294 (1972).

24. R.E. Kagarise and K.B. Whetsel, Spectrochim. Acta, 18, 341 (1962).

25. G.E. Maciel and J.J. Natterstad, J. Chem. Phys., 42, 2752 (1965).

26. W.D. Closseon and P.J. Orenski, J. Orq. Chem., 32, 3161 (1967).

27. G. Maes, Spectrosc. Lett., 16, 311 (1983) .

28. T.X. Carroll, S.R. Smith and T.D. Thomas, J. Am. Chem. Soc., 97, 659 (1975).

29. G.I.L. Jones and N.L. Owen, J. Mol. Struct., 18, 1 (1973).

30. H.S. Randhawa, Z. Phys. Chem. (Leipziq), 262, 561 (1981); C. Van Alsenoy and J.N. Scarsdale, J. Mol. Struct., 90, 297 (1982) .

31. W.B. Smith and H. Gilde, J. Polym. Sci., S45, 59 (1962).

32. G. Eaton, A.S. Pena-Nuñez and M.C.R. Symons, unpublished results.

33. A.S. Pena-Nuñez, Ph.D. Thesis, University of Leicester (1985) .

34. G. Eaton, Ph.D. Thesis, University of Leicester (1983).

35. M.C.R. Symons in Water and Aqueous Solutions (Colston Symposium 14-18 April, University of Bristol) (1985).

36. M.C.R. Symons, J.M. Harvey and S.E. Jackson, J. Chem. Soc., Faraday Trans. I, 76, 256 (1980).

37. G. Eaton and M.C.R. Symons, Faraday Symp. Chem. Soc., 17, 31 (1982) . 